\title{
Aislamiento de los microorganismos cultivables de la rizosfera de Ornithogalum umbellatum y evaluación del posible efecto biocontrolador en dos patógenos del suelo.
}

\author{
Solange Benítez ${ }^{1}$, Johanna Bentley ${ }^{1}$, Paula Bustamante ${ }^{1}$, \\ Ligia Consuelo Sánchez², Lucia Corrales² \\ ${ }^{1}$ Estudiantes de Bacteriología Universidad Colegio Mayor de Cundinamarca \\ ${ }^{2}$ Docentes investigadoras Universidad Colegio Mayor de Cundinamarca \\ Correspondencia: ligiasanchezle@gmail.com
}

Recibido: 22-07-07 / Aceptado: 17-10-07

\begin{abstract}
Resumen
Los microorganismos presentes en el suelo ejercen una acción específica cuando se relacionan con una especie vegetal. Ornithogalum umbellatum es una planta silvestre usada en el país como ornamental pero reconocida en otras partes del mundo por los componentes químicos del bulbo y la aplicación de estas sustancias en el tratamiento alternativo de diferentes enfermedades. Esta característica permitió plantear la hipótesis de que la microflora existente en la rizosfera podría tener posibles efectos biocontroladores en fitopatógenos del suelo y a realizar una evaluación del efecto antagónico in vitro con Botrytis cinerea y Sclerotinia sclerotiorum.

El estudio se realizó tomando 12 muestras de rizosfera y sembrándolas por duplicado en medios sólidos, agar papa dextrosa, agar Rosa de Bengala (con y sin antibiótico), agar yeast mold y agar Luria Bertani. Se aislaron 8 morfotipos de levaduras, 5 morfotipos de bacterias y 9 morfotipos de mohos; la mayoría de ellos demostraron antagonismo in vitro con los fitopatógenos seleccionados. Este estudio permite concluir que en la rizósfera de la planta Ornithogalum umbellatum se encuentran microorganismos que demostraron antagonismo in vitro y que podrían ser utilizados como biocontroladores de Botrytis cinerea y Sclerotinia sclerotiorum. Además, se observó que algunos de los morfotipos microbianos aislados presentaban un antagonismo muy discreto pero ocasionaban cambios en la estructura y color de las hifas de los hongos fitopatógenos utilizados; posiblemente la concentración influye sobre los mecanismos de biocontrol.
\end{abstract}

Palabras clave: biocontrol, crecimiento micelial, fitopatógenos, Ornithogalum umbellatum, rizosfera, Sclerotinia sclerotiorum.

\footnotetext{
Abstract

The microorganisms present in the ground exert a specific action when related to a vegetal species. Ornithogalum umbellatum is a wild plant used in the country as ornamental but it is recognized in other parts of the world by the chemical components that the bulb has and by the application of these substances for the alternative treatment of different diseases. In effect, this particularity is the one that leads the investigators to raise the hypothesis that the existing microflore in the rhizosphere could have possible biocontrolers effects in phytopathogens of the ground
} 
and to make an evaluation of the antagonistic effect in vitro with Botrytis cinerea and Sclerotinia sclerotiorum.

The study was made taking 12 samples from rhizosphere and seeding them by duplicate in solids average, agar dextrose potatoe, agar Bengal Rose, (with and without antibiotic), agar yeast mold and agar Luria Bertani. 8 morphotypes of leavenings, 5 morphotypes of bacteria and 9 morphotypes of moulds were isolated; most of them demonstrated antagonism in vitro with the selected phytopathogens. This study allows us to conclude that in the rhizosphere of the plant $\mathrm{O}$. umbellatum are microorganisms that demonstrated antagonism in vitro and that they could be used like biocontrolers of Botrytis cinerea and Sclerotinia sclerotiorum. In addition, it was observed that some of the isolated microbial morphotypes displayed a very discreet antagonism, but they caused changes in the structure and color of hyphae of the used phythopatogens fungi. It leads us to think that the concentration of the biocontroler influences the mechanisms of biocontrol.

Key words: biocontrol, Ornithogalum umbellatumrizosphere, phytophatogens, rhizosphere, Sclerotinia sclerotiorum.

\section{Introducción}

Ornithogalum umbelatum es una planta de la familia Hyacinthaceae más conocida por sus nombres comunes, leche de gallina o estrellita de Belén, pertenece al genero de plantas bulbosas europeas muy comunes en la región Mediterránea. La mayoría de las especies son fáciles de cultivar, no son exigentes; en Europa y Asia crece en habitats húmedos, como la rivera de los ríos y los arroyos, no crece a temperaturas extremas. En Colombia es considerada una planta silvestre que crece durante todo el año, sin condiciones agronómicas especiales y en la actualidad se está cultivando en campo e invernadero para ser utilizada como ornamental y puede durar mucho tiempo sin deteriorarse y conservando sus características que la hacen apetecible al público. Esta planta y algunas especies de este mismo género han sido estudiadas en otros países por el contenido de sustancias bioquímicas en el bulbo, compuestos flavinoides, glicósidos colestanos, glicósidos espirostaroles y ornithosaponinas A-D $(1,2)$ y a pesar de considerarse tóxicas, en dosis adecuadas han sido utilizadas como medicina alternativa para tratamiento de enfermedades siquiátricas y hematológicas como leucemias agudas $(3,4)$.

La importancia de la planta está en su bulbo y por ello los estudios de las estructuras que lo conforman, en particular la rizosfera, puede mostrar elementos valiosos sobre su comunidad microbiana situación que llevó a pensar que algunos de estos microorganismos podrían actuar como posibles biocontroladores de patógenos del suelo. El objetivo de este estudio fue aislar los microorganismos cultivables de la rizosfera y evaluar su posible efecto biocontrolador con dos fitopatógenos del suelo, Botrytis cinerea y Sclerotinia sclerotiorum por medio de pruebas de antagonismo in vitro.

Los resultados de esta investigación deben ser comprobados con estudios in vivo utilizando cultivos susceptibles a estos fitopatógenos, en particular hortalizas, frutales y tubérculos $(5,6)$, ya que las pudriciones que Botrytis cinerea y Sclerotinia sclerotiorum generan en estas especies vegetales, han sido causantes de pérdidas parciales y totales para agricultores de todo el país pero en especial en la Sabana de Bogotá, Cundinamarca y Boyacá. Establecida la identificación de los mejores controladores biológicos y comprobando su eficacia in vivo, este estudio sería una contribución a procesos de control biológico bien sea, con el uso de extractos en dosis controladas o estableciendo coberturas con esta especie vegetal.

\section{Materiales y métodos}

\section{Materiales Biológicos}

Muestras de rizosfera de la especie vegetal Ornithogalum umbellatum. Fitopatógenos Botrytis 
cinerea y Sclerotinia sclerotiorum obtenidos de suelo de hortalizas.

\section{Toma de muestra y aislamiento de posibles micro- organismos biocontroladores}

\section{Muestras de rizosfera de Ornithogalum umbellatum}

Las muestras se tomaron de un terreno ubicado en Suesca, Cundinamarca, Colombia, donde se cultiva Ornithogalum umbellatum para su comercialización como planta ornamental. Las condiciones fitosanitarias del cultivo eran óptimas, no se evidenciaron lesiones por enfermedad y tampoco se observó presencia de malezas. El agricultor manifestó no haber aplicado agroquímicos. El muestreo se realizó completamente al azar en 12 sitios de una parcela, en cada uno de ellos se extrajeron $15 \mathrm{~g}$ de suelo por muestra de rizosfera.

\section{Aislamiento microbiológico}

Se realizaron diluciones en base diez a partir de $1 \mathrm{~g}$ de cada una de las muestras (dil 1/10, 1/100 y 1/1000). De cada dilución, se sembraron $0.1 \mathrm{~mL}$ en cajas de agar Saboraud, Rosa de Bengala (con y sin antibiótico), agra papa dextrosa (PDA) por duplicado, en agar Luria Bertani (LB) y agar Yeast Mold (YM). Se incubaron por 7 días a $25^{\circ} \mathrm{C}$, para hongos filamentosos y 24 horas a $37^{\circ} \mathrm{C}$, para bacterias y levaduras. Luego se realizó una observación macroscópica y microscópica para la selección de morfotipos de levaduras, bacterias y mohos. Posteriormente, se realizaron aislamientos secundarios en agar PDA, YM y LB de todos los morfotipos microbiológicos seleccionados.

\section{Evaluación del posible efecto biocontrolador de los microorganismos aislados. Ensayo de antagonismo in vitro}

La metodología utilizada para este ensayo fue la de Carruthers y colaboradores (7) con algunas modificaciones de Uribe (8). Los morfotipos de levadura seleccionados fueron aislados en agar YM. Para los morfotipos de mohos se utilizó agar PDA y para bacterias se utilizó agar LB. Paralelamente, los hongos fitopatógenos se aislaron en agar PDA y se incubaron por 8 días a temperatura ambiente para asegurar su crecimiento y esporulación. El protocolo para realizar la prueba de antagonismo se describe a continuación:

1. Siembra de los morfotipos de bacterias y levaduras aisladas formando dos líneas paralelas en cajas de PDA e incubación a $37^{\circ} \mathrm{C}$ por 48 horas. En cada caja se sembraron dos morfotipos diferentes.

2. Los morfotipos de mohos aislados se colocaron a $2 \mathrm{~cm}$ del centro de las cajas de petri y se incubaron a temperatura ambiente por 8 días.

3. Siembra de testigos absolutos de cada uno de los morfotipos posibles controladores.

4. Una vez cumplido el tiempo de incubación, se tomó una porción de $0.5 \mathrm{~cm}$ de diámetro de los hongos fitopatógenos Botrytis cinerea y Sclerotinia sclerotiorum y se colocaron en el centro de la caja para los morfotipos de bacterias y levaduras y para los mohos a $2 \mathrm{~cm}$ del centro de la caja paralelos a los mohos posibles controladores. Se incubaron los ensayos a temperatura ambiente.

5. Siembra de testigos absolutos de los hongos fitopatógenos Botrytis cinerea y Sclerotinia sclerotiorum.

6. Lectura del crecimiento fúngico se llevó a cabo al segundo y sexto día para Botrytis cinerea y para Sclerotinia sclerotiorum al segundo y doceavo día de incubación.

7. El control negativo utilizado fue Escherichia coli.

\section{Resultados}

La tasa de crecimiento micelial del patógeno se dio en $\mathrm{cm} /$ día, se determinó teniendo en cuenta el radio de crecimiento micelial de la colonia fúngica calculando su magnitud mediante la expresión sugerida por Mead en 1993 (9).

$$
\text { T.C= }(\mathrm{Cf}-\mathrm{Ci}) /(\mathrm{Tf}-\mathrm{Ti})
$$




\begin{tabular}{|c|c|c|}
\hline \multicolumn{3}{|c|}{$\begin{array}{c}\text { T abla } 1 \text { Resultados del porcentaje de inhibición y tasa de } \\
\text { crecimiento micelial de Botrytis cinerea frente a morfotipos } \\
\text { bacterianos }\end{array}$} \\
\hline Aislamientos & \% Inhibición & T.C (cm/día) \\
\hline B2 & 66,6 & 0,2 \\
\hline B3 & 86,6 & 0,02 \\
\hline B5 & 55,5 & 0,3 \\
\hline B6 & 0 & 0,9 \\
\hline B7 & 64,4 & 0,22 \\
\hline Control (-) & 0 & 1 \\
\hline Testigo & 0 & 1 \\
\hline
\end{tabular}

T abla 2Resultados del porcentaje de inhibición y tasa de crecimiento micelial de Botrytis cinerea frente a morfotipos de levaduras.

\section{Aislamientos \% Inhibición T.C (cm/día)}

$\begin{array}{ccc}\text { L1 } & 71,1 & 0,125 \\ \text { L2 } & 0 & 1 \\ \text { L3 } & 55.5 & 0,225 \\ \text { L4 } & 62,2 & 0,77 \\ \text { L6 } & 0 & 1 \\ \text { L9 } & 0 & 0,9 \\ \text { L10 } & 0 & 0,9 \\ \text { L11 } & 0 & 0,9 \\ \text { ontrol (-) } & 0 & 1 \\ \text { Testigo } & 0 & 1\end{array}$

Donde:

Cf: es el crecimiento final (día seis, en caso de Botrytis cinerea y día 12, en el caso de Sclerotinia sclerotium) expresado en $\mathrm{cm}$.

Ci: es el crecimiento inicial (día uno) expresado en $\mathrm{cm}$.

Tf: es el tiempo final (día seis, en caso de Botrytis cinerea y día 12 , en el caso de $S$. sclerotium).

Ti: es el tiempo inicial (día uno).

El comportamiento de inhibición mostrado por los diferentes aislamientos se agrupó de la siguiente manera (6).

Negativo: ausencia de zona de inhibición o un porcentaje menor de $10 \%$ y crecimiento normal de la colonia fúngica, de forma similar al control.

Baja: ausencia de zona de inhibición o con un porcentaje entre 10-39\% y con disminución en el crecimiento de la colonia fúngica.

Media: ausencia de zona de inhibición o un porcentaje entre de 40-69\% y con disminución en el crecimiento de la colonia fúngica.
T abla 3Resultados del porcentaje de inhibición y tasa de crecimiento micelial de Sclerotinia sclerotiorum frente a morfotipos de bacterias.

\begin{tabular}{ccc}
\hline Aislamientos & $\%$ Inhibición & T.C (cm/dia) \\
\hline B2 & 42.8 & 0.15 \\
B3 & 82.8 & 0.01 \\
B5 & 2.8 & 0.25 \\
B6 & 45.7 & 0.13 \\
B7 & 28.5 & 0.21 \\
Controles (-) & Zero & 0.37 \\
Testigo & 0 & 0.35
\end{tabular}

T abla 4Resultados del porcentaje de inhibición y la tasa de crecimiento micelial de Sclerotinia sclerotiorum frente a morfotipos de levaduras.

$\begin{array}{ccc}\text { Aislamientos } & \text { \% Inhibición } & \text { T.C ( } \mathrm{cm} / \mathrm{dia}) \\ \text { L1 } & 42.8 & 0.17 \\ \text { L2 } & 11.4 & 0.25 \\ \text { L3 } & 22.8 & 0.2 \\ \text { L4 } & 62.8 & 0.05 \\ \text { L6 } & 28.5 & 0.21 \\ \text { L9 } & 0 & 0.32 \\ \text { L10 } & 17.1 & 0.26 \\ \text { L11 } & -11.4 & 0.34 \\ \text { Control (-) } & 0 & 0.37 \\ \text { Testigo } & 0 & 0.35\end{array}$

Positivo: presencia de zona de inhibición definida o en un porcentaje entre $70-100 \%$.

El porcentaje de inhibición se tomó a partir de la diferencia entre el máximo de crecimiento del control negativo $100 \%$ y el porcentaje de crecimiento obtenido por el patógeno.

\section{Pruebas microscópicas y bioquímicas para identificación fenotípica de los microorganismos biocontroladores.}

Se identificaron fenotípicamente los morfotipos de bacterias obtenidas a través de pruebas bioquímicas semiautomatizadas tipo BBL CRYSTAL ${ }^{\mathrm{TM}}$ y la identificación de los morfotipos de levaduras se utilizó el sistema automatizado Microscan. Para la identificación de los mohos seleccionados en general, se realizaron microcultivos respectivos incubados por 6 días a temperatura ambiente y la identificación se hizo por observación macroscópica y microscópica. 
T abla 5Resultados del porcentaje de inhibición y tasa de crecimiento micelial de Sclerotinia sclerotiorum frente a morfotipos de mohos.

\begin{tabular}{ccc} 
Aislamientos & $\%$ Inhibición & T.C (cm/día) \\
H1 & 8 & 0.18 \\
H4 & 64 & 0.05 \\
H5 & 68 & 0.03 \\
H7 & 44 & 0.06 \\
H8 & 84 & 0.01 \\
H12 & 72 & 0.03 \\
H14 & 32 & 0.14 \\
H16 & 80 & 0.01 \\
Testigo & 0 & 0.2 \\
\hline
\end{tabular}

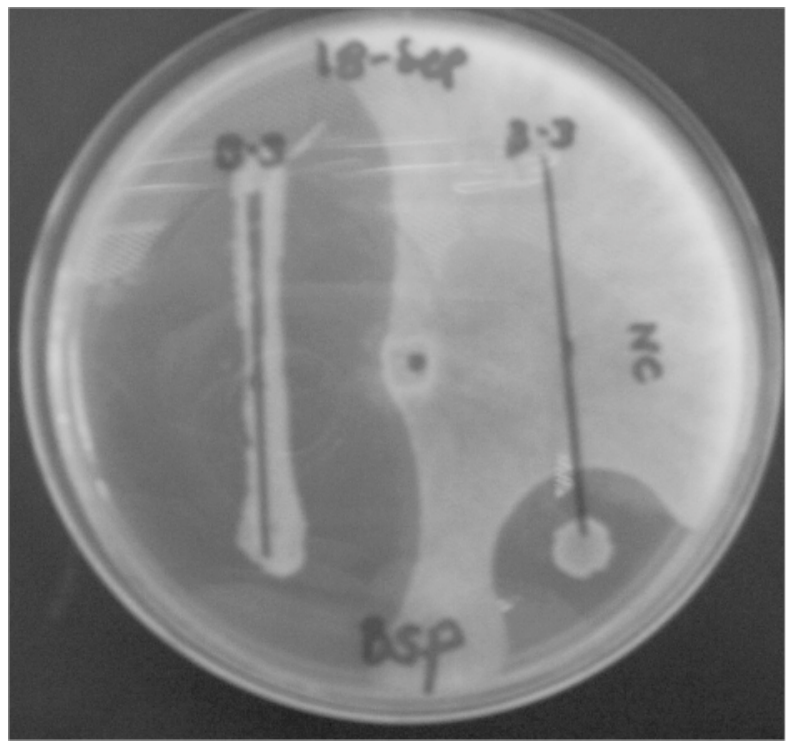

T abla 6Resultados del porcentaje de inhibición y tasa de crecimiento micelial de Botrytis cinerea frente a morfotipos de mohos.

\begin{tabular}{ccc} 
Aislamientos & \% Inhibición & T.C (cm/día) \\
H1 & 31.2 & 0.87 \\
H4 & 58.7 & 0.27 \\
H5 & 62.5 & 0.4 \\
H7 & 37.5 & 0.76 \\
H8 & 68.7 & 0.1 \\
H12 & 62.5 & 0.46 \\
H14 & 35 & 0.84 \\
H16 & 57.5 & 0.48 \\
Testigo & 0 & 1.5 \\
\hline
\end{tabular}

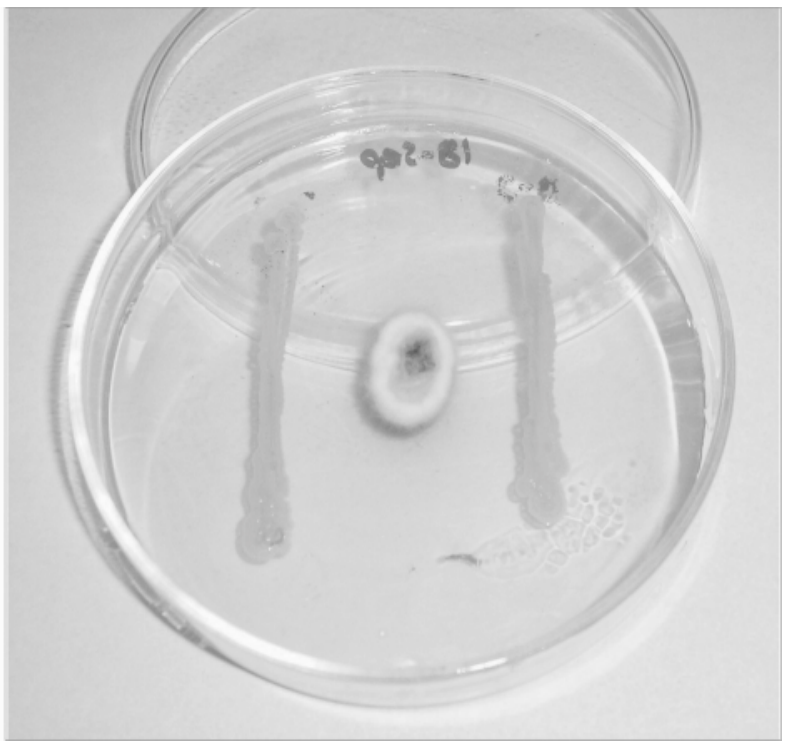

Figura 1. Pruebas de antagonismo del morfotipo B3 contra los dos fitopatógenos.

En total se aislaron 5 morfotipos de bacterias, 8 de levaduras y 8 mohos. En las pruebas de antagonismo in vitro de los aislamientos obtenidos contra Botrytis cinerea y Sclerotinia sclerotiorum se calculó la tasa de crecimiento micelial y el porcentaje de inhibición frente a bacterias, levaduras y mohos obteniendo los resultados que se muestran en las Tablas 1-6.

Los morfotipos bacterianos identificados fueron bacilos Gram positivos y se identificaron como: Bacillus brevis (B3), Bacillus sphaericus (B5), Bacillus pumilis (B7) y Bacillus sp (B2), Figura 1.
En la Figura 2 se observa el antagonismo de Sclerotinia sclerotiorum con el morfotipo L11.

\section{Discusión}

Aunque los porcentajes de inhibición presentan diferencias entre morfotipos aislados y con respecto a los dos patógenos, se identificaron todos los que presentaron porcentaje de inhibición con cualquiera de los dos patógenos teniendo en cuenta que la concentración del inóculo no fue considerada en este estudio y que in vivo podría tener un comportamiento diferente. Los morfotipos bacterianos identificados 


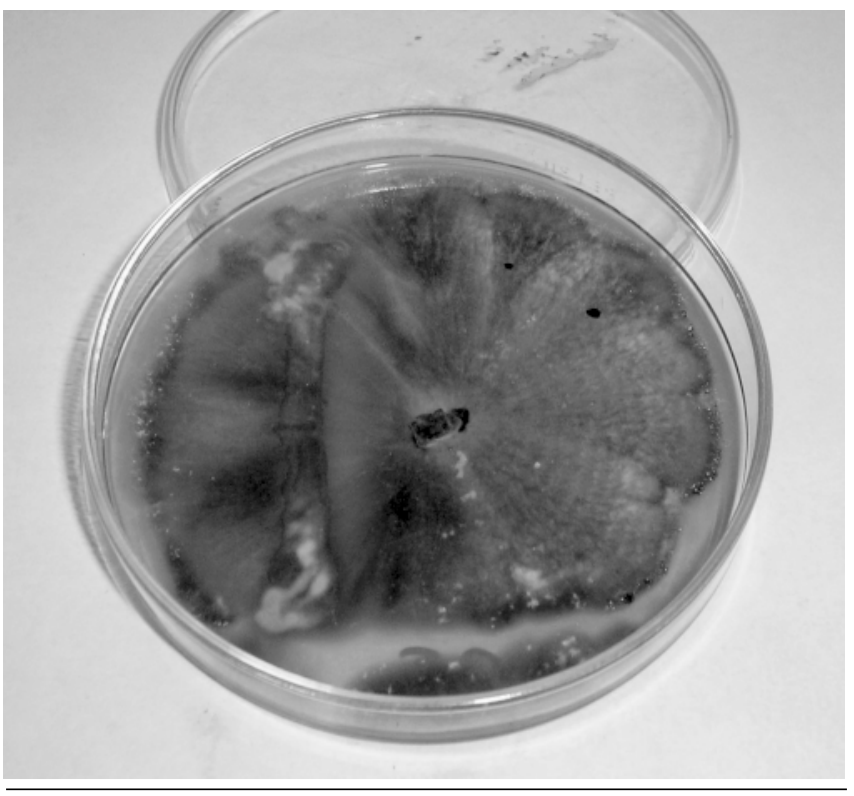

Figura 2. Efectos del morfotipo L11 sobre Sclerotinia sclerotiorum

fueron bacilos Gram positivos y se identificaron como: Bacillus brevis (B3), Bacillus sphaericus (B5), Bacillus pumilis (B7) y Bacillus sp (B2), Figura 1.

Los morfotipos de levadura con mejor comportamiento fueron el L1, L3 y L4. Su identificación fenotípica no fue posible con el sistema Microscan para levaduras por lo que se procedió a su congelación a $70^{\circ} \mathrm{C}$ para determinar su efecto biocontrolador in vivo $\mathrm{y}$ su posterior identificación por biología molecular de acuerdo con los resultados que se obtengan en esa fase. El morfotipo L11 y L4 además de inhibición originaron cambios en las características macroscópicas del hongo fitopatógeno. En la Figura 2 se observa el antagonismo de Sclerotinia. sclerotiorum con el morfotipo L11. Los morfotipos de mohos con mejor comportamiento para los dos hongos fitopatógenos fueron identificados así: Absidia sp (H16), Penicillum sp (H8), Fusarium sp (H5), Penicillum sp (H12).

La rapidez del crecimiento de los dos fitopatógenos fue diferente y este comportamiento permitió evidenciar un número mayor de especies biocontroladoras para Sclerotinia sclerotiorum (10). El crecimiento masivo y rápido de Botrytis cinerea hizo que algunas de las especies biocontroladoras no pudieran establecerse en el medio antes que ella y por lo tanto sólo los microorganismos que crecieron en un tiempo menor al del patógeno fueron los que evidenciaron mejor comportamiento. Se ha demostrado que Botrytis cinerea tiene mayor capacidad de infectar a la planta huésped, y por lo tanto tiene mayor prevalencia y distribución en cultivos de interés comercial (11).

Las tres especies de Bacillus identificadas han sido reportadas como biocontroladoras. Es evidente que cada uno de los morfotipos aislados debe demostrar capacidad biocontroladora in vivo, razón por la cual este proyecto tiene una segunda fase en la que se realizaran las pruebas de patogenicidad utilizando las hortalizas de donde fueron obtenidos los patógenos y aplicando, según protocolos establecidos, los diferentes morfotipos identificados para proceder a posteriores pruebas de biología molecular con los que demuestren mejor capacidad biocontroladora.

\section{NOVA}

\section{Referencias}

1. AzziorI O, Braemer R, Paris M. Glucosylflavones in the genus Ornithogalum. Biochem Syst Ecol 1989;17: 449-450.

2. Kuroda M, Mimaki Y, Yokosuka A, Hasegawa F, Sashida Y. Cholestane glycosides from the bulbs of Ornithogalum thyrsoides and their cytotoxic activity against HL-60 leukemia cells. J Nat Prod 2002; 65:1417-1423.

3. Mimaki Y, Kuroda M, Sashida Y, Hirano T, Oka K, Dobashi A. Three Novel Rearranged Cholestane Glycosides from Ornithogalum saundersiae Bulbs and Their Cytostatic Activities on Leukemia HL-60 and MOLT-4 Cells. Tetrahedron Lett 1996;37:1245-1248.

4. Hirano T, Oka K, Mimaki Y, Kuroda M, Sashida Y. Potent growth inhibitory activity of a novel ornlthogalum cholestane glycoside on human cells: induction of apoptosis in promyelocytic leukemia HL-60 cells. Life Sciences. 1996; 58:739-798.

5. Fernández O, Vega L. Microorganismos antagonistas para el control fitosanitario. Manejo integrado de plagas 2001; 62:96-100.

6. Bautista G. Determinación de la asociación y antagonismo contra $R$. solani de aislamientos nativos de Pseudomonas fluoresens en un cultivo de papa Solanum phuroja en condiciones de invernadero. Universidad Nacional. Maestría de ínter facultades en Microbiología. 2000.

7. Carruthers F, Connere A, Mahonty H. Identification of genetic locus in P.aureofacions involved I fungal inhibition. Applied. Env Microbiol. 1994;60:71-75.

8. Uribe D, Ortiz E, Portillo M, Bautista G, Ceron J. Diversidad de pseudomonas fluorescentes en cultivos de papa de la región cundí boyacense y su actividad antagonista in vitro sobre Rhizoctonia solani. Rev. Colombiana de Biotecnología. 1999; 6: No 1. 
9. Mead G, Hudson W, Hinton M. Microbiological survey of five poultry processing plants in the UK. Br Poult Sci. 1993;34:497-503.

10. Cundom M, Mazza S, Mazzanti M, Gutierrez S, Coutinho M. Actividad antagónica in vitro de Hongos Saprofitos sobre $S$. sclerotiorum. Cátedra de Fitopatología, Facultad de ciencias agrarias, UNNE Argentina. 1998.
11. Molina G, Forero de la R C, Torres E.. Incidencia de Infecciones Quiescientes de Moho Gris, causado por Botrytis cinerea, en flores, en frutos de mora de Castilla Rubus glaucus. Fitopatología colombiana 2004; 28: 49-56.
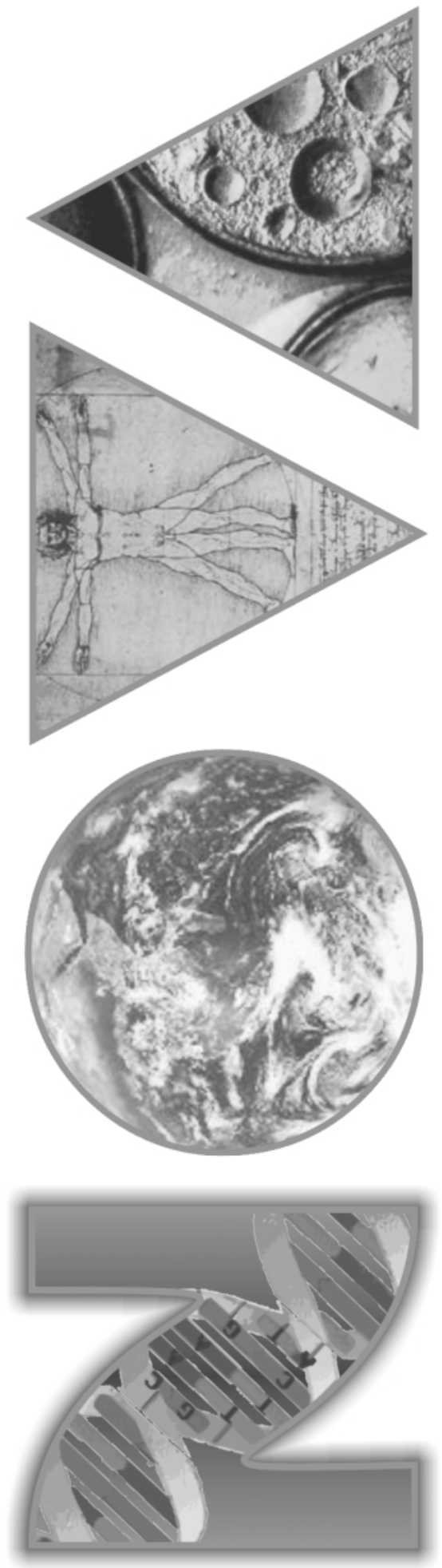